УДК 665.625.6

ИНСТРУМЕНТЫ ДЛЯ АВТОМАТИЗИРОВАННОГО РАСЧЕТА ДАВЛЕНИЙ ИСПЫТАНИЙ, КОНТРОЛЯ СВАРНЫХ ШВОВ, ТЕРМООБРАБОТКИ СТЫКОВ ТРУБОПРОВОДОВ В СРЕДЕ САПР AVEVA PDMS/E3D

\title{
TOOLS FOR AUTOMATED CALCULATION OF TEST PRESSURES, WELDING CONTROL, PIPELINE JOINTS HEAT TREATMENT IN CAD AVEVA PDMS/E3D
}

В.Р. Нигматуллин, Д.М. Костенков, А.И. Коскина, Т.Р. Загидуллин, А.Р. Дашкина, С.М. Мавлютова

Уфимский государственный нефтяной технический университет, г. Уфа, Российская Федерация

Vil R. Nigmatullin, Dmitriy M. Kostenkov, Alena I. Koskina, e-mail: rushaniya_romanchuk@mail.ru

Аннотация. В ходе проектных работ возникают задачи подбора и расчета давлений гидроиспытаний и пневмоиспытаний трубопроводов, определения контроля сварных швов, а также термообработки стыковых и сварных соединений трубопроводов.

Гидравлические и пневматические испытания - комплекс мероприятий, которые могут проводиться на разных этапах эксплуатации трубопроводов, но чаще всего эти испытания выполняются сразу после прокладки коммуникации, перед её запуском. Инженерные сети, которые работают под давлением, в обязательном порядке должны проверяться на различные дефекты [2]. Такие испытания способны выявить определённые несоответствия труб или комплектующих к ним стандартам качества, прописанным в законах. Проведение проверочных мероприятий является 
необходимым пунктом эксплуатации оборудования, работающего под давлением.

Проверочное давление нагнетается в трубопроводе медленно и плавно, чтобы не вызвать гидроудар или не создать другую аварийную ситуацию. Показатели давления превышают стандартные эксплуатационные нормы. Проведение процедуры испытаний необходимо, чтобы предотвратить возникновение аварийной ситуации.

С целью ускорения выполнения работ и сокращения влияния человеческого фактора разработана программа (на внутреннем скриптовом языке Aveva PML) для автоматизации расчетов и получения необходимых параметров.

Данные инструменты были апробированы в рамках созданного в УГНТУ «Технологического центра компании AVEVA».

Разработанная программа позволяет быстро и качественно получать параметры для большого количества трубопроводов, спроектированных в CAПР Aveva PDMS/E3D c возможностью в дальнейшем отразить полученные величины в текстовой части на изометрических чертежах или в ведомости трубопроводов.

Abstract. In the course of design work, problems arise of selecting and calculating the pressure of hydraulic tests and pneumatic testing of pipelines, control of welds, as well as heat treatment of butt and welded joints of pipelines.

Hydraulic and pneumatic tests are a set of measures that can be carried out at different stages of pipeline operation, but most often these tests are carried out immediately after laying the communication, before it is launched. Engineering networks that operate under pressure must be checked for various defects. Such tests are able to identify certain discrepancies in the pipes or their components to the quality standards prescribed in the laws. Conducting verification activities is a necessary point of operation of equipment operating under pressure.

Test pressure is pumped slowly and smoothly in the pipeline so as not to cause a water hammer or create another emergency. Pressure indicators exceed 
standard operating standards. A test procedure is necessary to prevent an emergency.

In order to accelerate the execution of work and reduce the influence of the human factor, a program has been developed (in the Aveva PML internal scripting language) to automate calculations and obtain the necessary parameters.

These tools were tested in the framework of the AVEVA Technology Center, Ufa State Petroleum Technological University (Ufa, Russian Federation).

The developed program allows you to quickly and efficiently obtain parameters for a large number of pipelines designed in the Aveva PDMS/E3D CAD system with the ability to further reflect the obtained values in the text part on isometric drawings or in the pipeline list.

Ключевые слова: CAПР Aveva PDMS/E3D; атрибуты; пневмоиспытания; гидроиспытания; контроль сварных швов; термообработка

Key words: Aveva PDMS/E3D CAD; attributes; pneumatic testing; hydraulic testing; weld inspection; heat treatment

В ходе проектных работ возникают задачи подбора и расчета давлений гидроиспытаний и пневмоиспытаний трубопроводов, определения степени контроля сварных швов, а также термообработки стыковых и сварных соединений трубопроводов [1].

Гидравлические и пневматические испытания - комплекс мероприятий, которые могут проводиться на разных этапах эксплуатации трубопроводов, но чаще всего эти испытания выполняются сразу после прокладки коммуникации, перед её запуском. Инженерные сети, которые работают под давлением, в обязательном порядке должны проверяться на различные дефекты [2]. Такие испытания способны выявить определённые 
несоответствия труб или комплектующих к ним стандартам качества, прописанным в законах. Проведение проверочных мероприятий является необходимым пунктом эксплуатации оборудования, работающего под давлением.

Проверочное давление нагнетается в трубопроводе медленно и плавно, чтобы не вызвать гидроудар или не создать другую аварийную ситуацию. Показатели давления превышают стандартные эксплуатационные нормы. Проведение процедуры испытаний необходимо, чтобы предотвратить возникновение аварийной ситуации.

В системе автоматизированного проектирования Aveva отсутствует встроенная функциональность по расчету и подбору необходимых величин, поэтому с целью ускорения выполнения работ и сокращения влияния человеческого фактора разработана программа (на внутреннем скриптовом языке Aveva PML) для автоматизации расчетов и получения необходимых параметров.

Данные инструменты были апробированы в рамках созданного в УГНТУ «Технологического центра компании AVEVA».

Основной вид главной формы графического интерфейса показан на рисунке 1.

Кратко опишем основные решения, примененные в разработанной программе.

ГОСТ 32569-2013 регламентирует величину пробного давления на прочность и плотность, однако для трубопроводов, содержащих пар, газ (в газообразном, сжиженном состоянии), воду или конденсат, применяются Федеральные нормы и правила в области промышленной безопасности «Правила промышленной безопасности опасных производственных объектов, на которых используется оборудование, работающее под избыточным давлением» (ФНиП). 


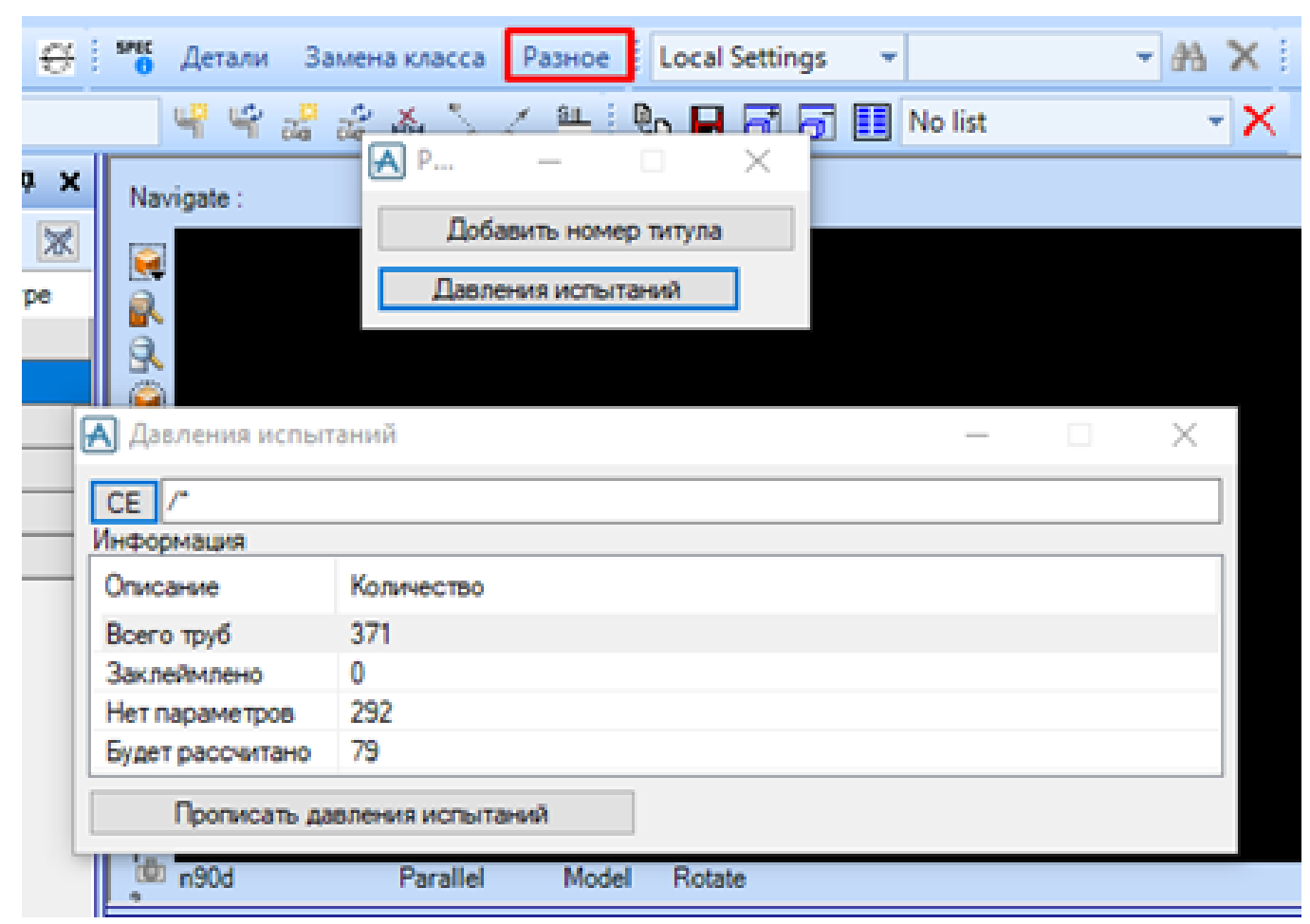

Рисунок 1. Основной вид разработанного инструмента

Величина пробного давления на прочность (гидравлическим или пневматическим способом) по ГОСТ 32569-2013 должна быть не менее величины, которая выбирается как большее из двух значений:

$$
P_{\text {mp }}=1,25 P \frac{[\sigma]_{20}}{[\sigma]_{t}} \text { (но не менее } 0,2 \text { МПа) }
$$

или

$$
P_{\text {mp }}=1,43 P \text {, }
$$

где $P$-расчетное давление трубопровода, МПа;

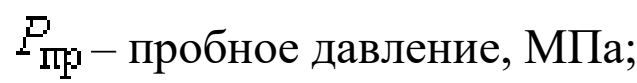

$[\sigma]_{20}$ - допустимое напряжение для материала трубопровода при $20{ }^{\circ} \mathrm{C}$;

$[\sigma]_{t}$ - допустимое напряжение для материала трубопровода при максимальной положительной расчетной температуре.

Отношение $\frac{[\sigma]_{20}}{[\sigma]_{t}}$ принимается как меньшее значение для материалов всех элементов трубопровода, работающих под давлением. 
Минимальная величина пробного давления по ФНиП при гидравлическом испытании трубопроводов пара и горячей воды, их блоков и отдельных элементов должна составлять 1,25 рабочего давления, но не менее 0,2 МПа.

Пробное давление по ФНиП при пневматическом испытании определяется по формуле:

$$
P_{n p}=1,15 P \frac{[\sigma]_{20}}{[\sigma]_{t}},
$$

где $P$ - рабочее давление.

При выборе допускаемого напряжения для материала трубопровода при максимальной положительной расчетной температуре $[\sigma]_{t}$ используются ГОСТ Р 52857.1 - 2007 [3] и РД 10-249-98 [4]. В алгоритме учитывается возможность применения нескольких материалов в рамках одного трубопровода. Также применяется линейная интерполяция для более точного получения величины $[\sigma]_{t}$.

Испытания на герметичность с определением падения давления выполняют согласно ГОСТ 32569-2013. Дополнительное испытание на герметичность проводят давлением, равным рабочему, а для вакуумных

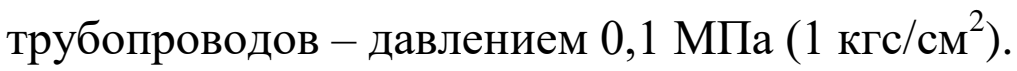

Результаты дополнительного пневматического испытания на герметичность смонтированных технологических трубопроводов, прошедших ремонт, связанный с разборкой или сваркой, признаются удовлетворительными, если скорость падения давления окажется не более $0,1 \%$ за 1 ч для трубопроводов группы А и вакуумных и $0,2 \%$ за 1 ч для трубопроводов группы Б(а), Б(б).

Параметр контроля сварных швов и стыковых соединений подбирался согласно алгоритму (таблица 1), соответствующему ГОСТ 32569-2013. 
Таблица 1. Принятый алгоритм выбора степени контроля сварных швов и стыковых соединений

\begin{tabular}{|c|c|}
\hline Контроль, \% & Условия \\
\hline 100 & $\begin{array}{l}\text { 1) Расчетное давление более } 10 \text { МПа. } \\
\text { 2) Блоки I категории взрывоопасности. } \\
\text { 3) Категория трубопровода I и минимальная } \\
\text { расчетная температура меньше }-70{ }^{\circ} \mathrm{C} . \\
\text { 4) Категория трубопровода I, группа А(а). } \\
\text { 5) Трубопроводы пара, конденсата, горячей воды, } \\
\text { если в них есть катушки с наружным диаметром, } \\
\text { большим или равным } 200 \text { мм и толщиной стенки } \\
\text { менее } 15 \text { мм }\end{array}$ \\
\hline 20 & Категория I, все остальные случаи \\
\hline 10 & Категория II \\
\hline 2 & Категория III \\
\hline 1 & Категория IV \\
\hline $\begin{array}{c}\text { ПОК } \\
\text { (Пооперационный } \\
\text { контроль) }\end{array}$ & Категория V \\
\hline
\end{tabular}

Параметр необходимости термообработки сварных стыков выбирался согласно алгоритму (таблица 2), аналогично соответствующему ГОСТ 32569-2013.

Полученный в ходе работы результат (рисунки 2 и 3) позволяет быстро и качественно получить параметры для большого количества трубопроводов, спроектированных в CAПP Aveva PDMS/E3D, а также в дальнейшем отразить полученные величины в текстовой части на изометрических чертежах или в ведомости трубопроводов. 
Таблица 2. Принятый алгоритм выбора необходимости термообработки сварных стыков

\begin{tabular}{|l|l|c|}
\hline \multicolumn{1}{|c|}{ Условие 1 } & \multicolumn{1}{|c|}{ Условие 2 } & $\begin{array}{c}\text { Необходимость } \\
\text { термообработки }\end{array}$ \\
\hline $\begin{array}{l}\text { жаропрочная сталь 15ХМ } \\
\text { и сталь 15Х5М }\end{array}$ & \multicolumn{1}{|c|}{ да } \\
\hline углеродистая сталь & $\begin{array}{l}\text { если параметр } \\
\text { «межкристаллитная коррозия» } \\
\text { установлен }\end{array}$ & да \\
\hline углеродистая сталь & $\begin{array}{l}\text { если параметр } \\
\text { «межкристаллитная коррозия» не } \\
\text { установлен }\end{array}$ & нет \\
\hline $\begin{array}{l}\text { стали нержавеющие } \\
\text { и содержащие молибден }\end{array}$ & $\begin{array}{l}\text { если параметр } \\
\text { «межкристаллитная коррозия» } \\
\text { установлен }\end{array}$ & да \\
\hline $\begin{array}{l}\text { стали нержавеющие } \\
\text { и содержащие молибден }\end{array}$ & $\begin{array}{l}\text { если параметр } \\
\text { «межкристаллитная коррозия» } \\
\text { установлен и максимальная } \\
\text { расчетная температура > 350 }{ }^{\circ} \mathrm{C}\end{array}$ & да \\
\hline независимо от класса & $\begin{array}{l}\text { если у трубы материал - } \\
\text { сталь 09Г2С и катушки толщиной } \\
\text { стенки > 30 мм }\end{array}$ & да \\
\hline независимо от класса & $\begin{array}{l}\text { если у трубы есть катушки } \\
\text { толщиной стенки > 36 мм }\end{array}$ & да \\
\hline остальные случаи & нет \\
\hline
\end{tabular}

\begin{tabular}{|c|c|c|c|}
\hline & Начменование продукта & \multicolumn{2}{|c|}{ Водяной пар низкого даВленчя } \\
\hline & \multirow{2}{*}{ Рабочче условия } & Давленче, МПа (чзб.) & 0,6 \\
\hline & & Temnepamypa, c & 158 \\
\hline & \multirow{2}{*}{ Расчетные усповия } & Давленче, МПа (чзб.) & 1,6 \\
\hline & & Tемпература, ; & 300 \\
\hline \multirow{4}{*}{ 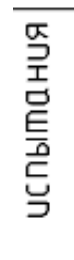 } & \multirow{2}{*}{$\begin{array}{l}\text { на прочность/ } \\
\text { плотноость, МПа }\end{array}$} & Bodoū & $0.75 / 0.6$ \\
\hline & & B0здyх0M & $-1-$ \\
\hline & \multirow{2}{*}{$\begin{array}{l}\text { с определенчем } \\
\text { паденчя ӘаВленчя, МПа }\end{array}$} & воздухом & - \\
\hline & & \% паденчя & - \\
\hline
\end{tabular}

Рисунок 2. Результаты вычисления давлений испытаний трубопровода 


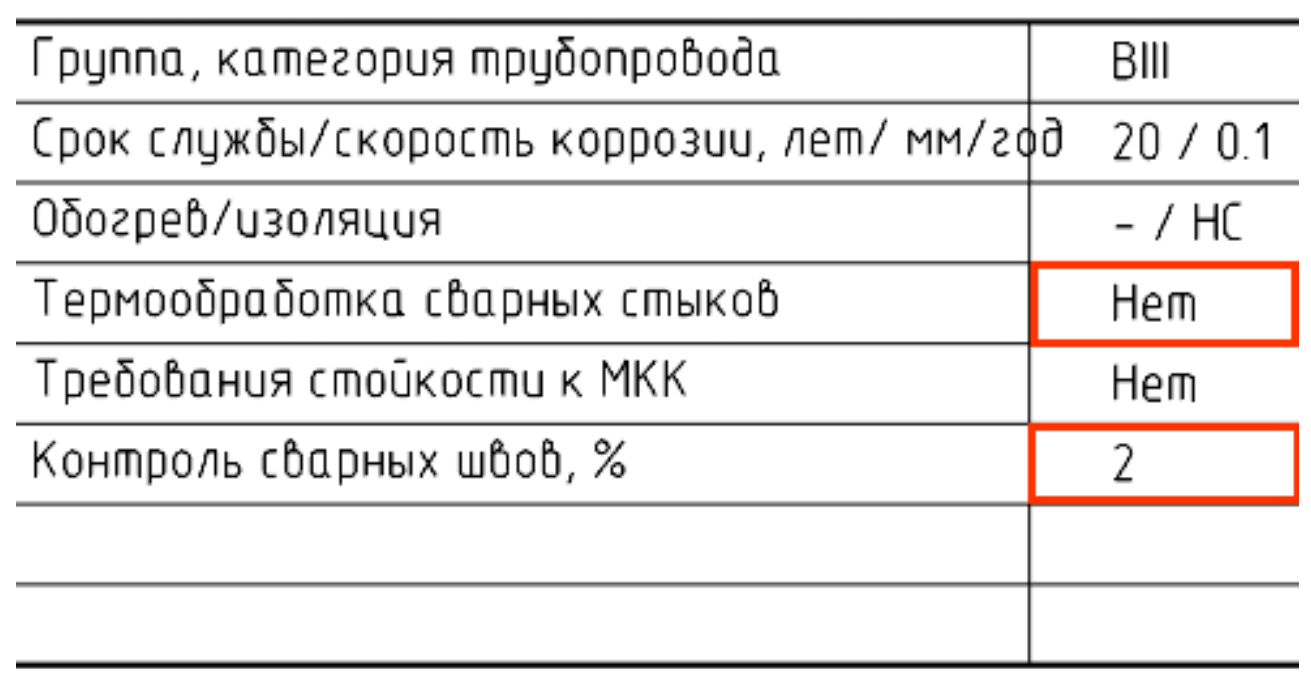

Рисунок 3. Отображение результата вычисления степени контроля сварных швов и необходимости термообработки

\section{Вывод}

Разработанная программа позволяет быстро и качественно получать параметры для большого количества трубопроводов, спроектированных в CAПP Aveva PDMS/E3D c возможностью в дальнейшем отразить полученные величины в текстовой части на изометрических чертежах или в ведомости трубопроводов.

\section{Список используемых источников}

1. ГОСТ 32569-2013. Трубопроводы технологические стальные. Требования к устройству и эксплуатации на взрывопожароопасных и химически опасных производствах. М.: Стандартинформ, 2015. 131 с.

2. Приказ № 116. Правила промышленной безопасности опасных производственных объектов, на которых используется оборудование, работающее под избыточным давлением / Федеральная служаы по экологическому, технологическому и атомному надзору. 2014. 254 с.

3. ГОСТ Р 52857.12-2007. Сосуды и аппараты. Нормы и методы расчета на прочность. Требования к форме представления расчетов на прочность, выполняемых на ЭВМ. М.: Стандартинформ, 2008. 7 с. 
4. РД 10-249-98. Нормы расчета на прочность стационарных котлов и трубопроводов пара и горячей воды. М.: ЗАО «Научно-технический центр исследований проблем промышленной безопасности», 2010. 344 с.

\section{References}

1. GOST 32569-2013. Truboprovody tekhnologicheskie stal'nye. Trebovaniya $\mathrm{k}$ ustroistvu i ekspluatatsii na vzryvopozharoopasnykh i khimicheski opasnykh proizvodstvakh [State Standard 32569-2013. Technological Steel Pipelines. Requirements for the Device and Operation in Explosive and Chemically Hazardous Industries]. Moscow, Standartinform Publ., 2015. 131 p. [in Russian].

2. Prikaz № 116. Pravila promyshlennoi bezopasnosti opasnykh proizvodstvennykh ob"ektov, na kotorykh ispol'zuetsya oborudovanie, rabotayushchee pod izbytochnym davleniem [Order No. 116. Rules of Industrial Safety of Hazardous Production Facilities that use Equipment Operating under Excessive Pressure]. 2014. 254 p. [in Russian].

3. GOST R 52857.12-2007. Sosudy i apparaty. Normy i metody rascheta na prochnost'. Trebovaniya $\mathrm{k}$ forme predstavleniya raschetov na prochnost', vypolnyaemykh na EVM [State Standard R 52857.12-2007. Vessels and Apparatus. Norms and Methods of Strength Calculation. Requirements for Representation of the Strength Calculations Carried out on the Computer]. Moscow, Standartinform Publ., 2008. 7 p. [in Russian].

4. RD 10-249-98. Normy rascheta na prochnost' statsionarnykh kotlov i truboprovodov para i goryachei vody [RD 10-249-98. Strength Calculation Norms for Stationary Boilers and Steam and Hot Water Pipelines]. Moscow, ZAO «Nauchno-tekhnicheskii tsentr issledovanii problem promyshlennoi bezopasnosti» Publ., 2010. 344 p. [in Russian]. 


\section{Сведения об авторах}

\section{About the authors}

Нигматуллин Виль Ришатович, канд. техн. наук, доцент, заведующий кафедрой «Комплексный инжиниринг и компьютерная графика», УГНТУ, г. Уфа, Российская Федерация

Vil R. Nigmatullin, Candidate of Engineering Sciences, Associate Professor, Head of Integrated Engineering and Computer Graphics Department, USPTU, Ufa, Russian Federation

e-mail: ikafedraig@mail.ru

Костенков Дмитрий Михайлович, ассистент кафедры «Комплексный инжиниринг и компьютерная графика», УГНТУ, г. Уфа, Российская Федерация

Dmitriy M. Kostenkov, Assistant of Integrated Engineering and Computer Graphics Department, USPTU, Ufa, Russian Federation

e-mail: dmikoss@gmail.com

Коскина Алёна Игоревна, магистрант кафедры «Комплексный инжиниринг и компьютерная графика», УГНТУ, г. Уфа, Российская Федерация

Alena I. Koskina, Undergraduate Student of Integrated Engineering and Computer Graphics Department, USPTU, Ufa, Russian Federation e-mail: koskina.alena@gmail.com

Загидуллин Талгат Радикович, магистрант кафедры «Комплексный инжиниринг и компьютерная графика», УГНТУ, г. Уфа, Российская Федерация

Talgat R. Zagidullin, Undergraduate Student of Integrated Engineering and Computer Graphics Department, USPTU, Ufa, Russian Federation e-mail: ZagidullinTalgat@gmail.com 
Дашкина Алина Рафаилевна, магистрант кафедры «Технология нефти и газа», УГНТУ, г. Уфа, Российская Федерация

Alina R. Dashkina, Undergraduate Student of Oil and Gas Processing Department, USPTU, Ufa, Russian Federation

e-mail: dashkina_alinochka@mail.ru

Мавлютова Светлана Мазитовна, ассистент кафедры «Комплексный инжиниринг и компьютерная графика», УГНТУ, г. Уфа, Российская Федерация

Svetlana M. Mavlyutova, Assistant of Integrated Engineering and Computer Graphics Department, USPTU, Ufa, Russian Federation

e-mail: mavsveta@mail.ru 